\title{
NUMERICALLY ANALYZING NONLINEAR DYNAMIC DEFORMATION AND LOSS OF STABILITY OF PRESTRESSED COMPOSITE CYLINDRICAL SHELLS
}

\section{LEONID A. IGUMNOV ${ }^{1,2}$, NIKOLAI A. ABROSIMOV ${ }^{1}$, ALEXANDER V. ELESIN AND NADEZHDA S. DYUKINA ${ }^{1}$}

\author{
${ }^{1}$ Research Institute for Mechanics, National Research Lobachevsky State University of Nizhny \\ Novgorod \\ Gagarin Avenue 23, Nizhny Novgorod, 603950, Russia \\ ndyukina@inbox, http://eng.unn.ru \\ ${ }^{2}$ Research and Education Mathematical Center "Mathematics for Future Technologies" \\ Gagarin Avenue 23, Nizhny Novgorod, 603950, Russia \\ igumnov@mech.unn.ru, http://eng.unn.ru
}

Key words: Composite Materials, Nonlinear Deformation, Stability, Numerical Methods .

\begin{abstract}
Within the framework of the applied shell theory, an energetically consistent resolving system of equations is formulated and a complex numerical method is developed that allows solving both quasi-static and dynamic problems of nonlinear non-axisymmetric deformation and loss of stability of composite cylindrical shells within the framework of an explicit variational-difference scheme. The reliability and accuracy of the proposed method are justified by comparing numerical calculations with experimental data. For various reinforcement structures, the analysis of the characteristic spatial configurations and critical loads of the loss of stability of fiberglass cylindrical shells is carried out, depending on the amount of preloading by quasi-static internal pressure and subsequent loading by axial dynamic compression.
\end{abstract}

\section{INTRODUCTION}

Due to the high strength and stiffness characteristics, composite materials are widely used in the creation of rational structures in various fields of modern technology. During operation, structural elements made of composite materials can be exposed to combined dynamic and static loads, which leads to considerable shape changes and loss of stability of structural elements. To effectively use the potential of composite materials, a comprehensive study of the dynamic deformation and loss of stability of structural elements made of composite materials under combined quasi-static and dynamic influences is necessary.

The research available in this direction is usually devoted to the analysis of the nonlinear behavior and loss of stability of cylindrical shells made of traditional isotropic materials [1-5]. The article [1] presents the results of an experimental and theoretical study of the instability region of a cylindrical steel shell under pulsed loading by external pressure in combination with external (or internal) static pressure. [2] presents the results of experimental studies of 
the effect of internal static pressure and the loading rate on the stability of cylindrical aluminum shells under pulsed loading by external pressure.

An experimental analysis of the buckling of thin-walled cylindrical shells under local impulse loading by external pressure and different values of axial static compression forces is presented in [3]. In [4], the results of an experimental study of the stability of cylindrical shells exposed to axial static forces and a pressure wave incident in the direction of the longitudinal axis are presented.

A numerical study of the process of loss of stability of composite cylindrical shells under dynamic loads was considered in [6-10].

The relevance of the presented work is since the nonlinear spatial problems of dynamic deformation and loss of stability of preloaded composite cylindrical shells are clearly insufficiently studied [6].

This paper presents the methodology and results of a numerical study of nonlinear unsteady deformation and loss of stability of composite cylindrical shells under the combined action of quasi-static and dynamic loads.

\section{PROBLEM FORMULATION AND SOLUTION METHOD}

Let us consider a cylindrical shell formed by angle-ply winding of a unidirectional composite material. Components of the nonlinear strain tensor in the applied theory of cylindrical shells can be determined on the basis of the simplest quadratic version of the nonlinear theory of elasticity. The physical relations for the elef formulated on the basis An energetically consis shells and respective boundar full functional of she11 energ according to the characteristic kink of the action amplitude-maximum deflection curve.

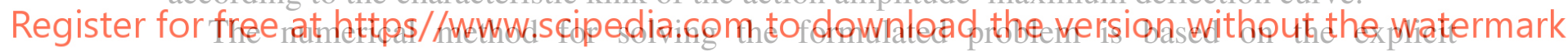
variational-difference scheme [12]. In this case, the quasi-static loading mode is simulated by specifying the internal pressure as a linearly growing function reaching a stationary value during three vibration periods of a cylindrical composite shell in the lowest form.

\section{RESULTS OF RESEARCH}

To substantiate the reliability and accuracy of the proposed method, numerical calculations are compared with experimental data [2] on the dynamic stability of isotropic cylindrical shells preloaded with internal pressure and subsequent external pressure pulse with different velocities.

The geometric and physico-mechanical parameters of the shell material were equal: $R / h=104 ; h=0.0005 \mathrm{~m} ; L / R=1,9 ; E=73 \mathrm{GPa} ; \nu=0.3, \rho=2700 \mathrm{~kg} / \mathrm{m}^{3}, \sigma_{*}=0.37 \mathrm{GPa}$; $g=0.6 \mathrm{GPa}, \mathrm{L}-$ the length of the forming shell.

The static internal pressure was created by compressed air, and the pulse pressure was carried out as a result of electrohydraulic discharge when the calibrated copper wires were detonated [2]. At the same time, the fixing of the edges of the shell was close to a hard 
pinching.

Figure 1 shows the experimental and calculated dependences of the dynamism coefficient $K=\frac{F_{3}^{*}}{F_{3}^{0}}$ from the loading speed by the external pressure pulse $\dot{F}_{3}^{-}\left(F_{3}^{*}, F_{3}^{0}\right.$ - critical loads of stability loss under dynamic and static external pressure, respectively). These results are obtained at static internal pressure $F_{3}^{+}$, which in dimensionless form is defined by the expression $\bar{F}_{3}^{+}=\frac{F_{3}^{+}}{E}\left(\frac{R}{h}\right)^{2}$ and in this case it is equal to $\bar{F}_{3}^{+}=0.07$.

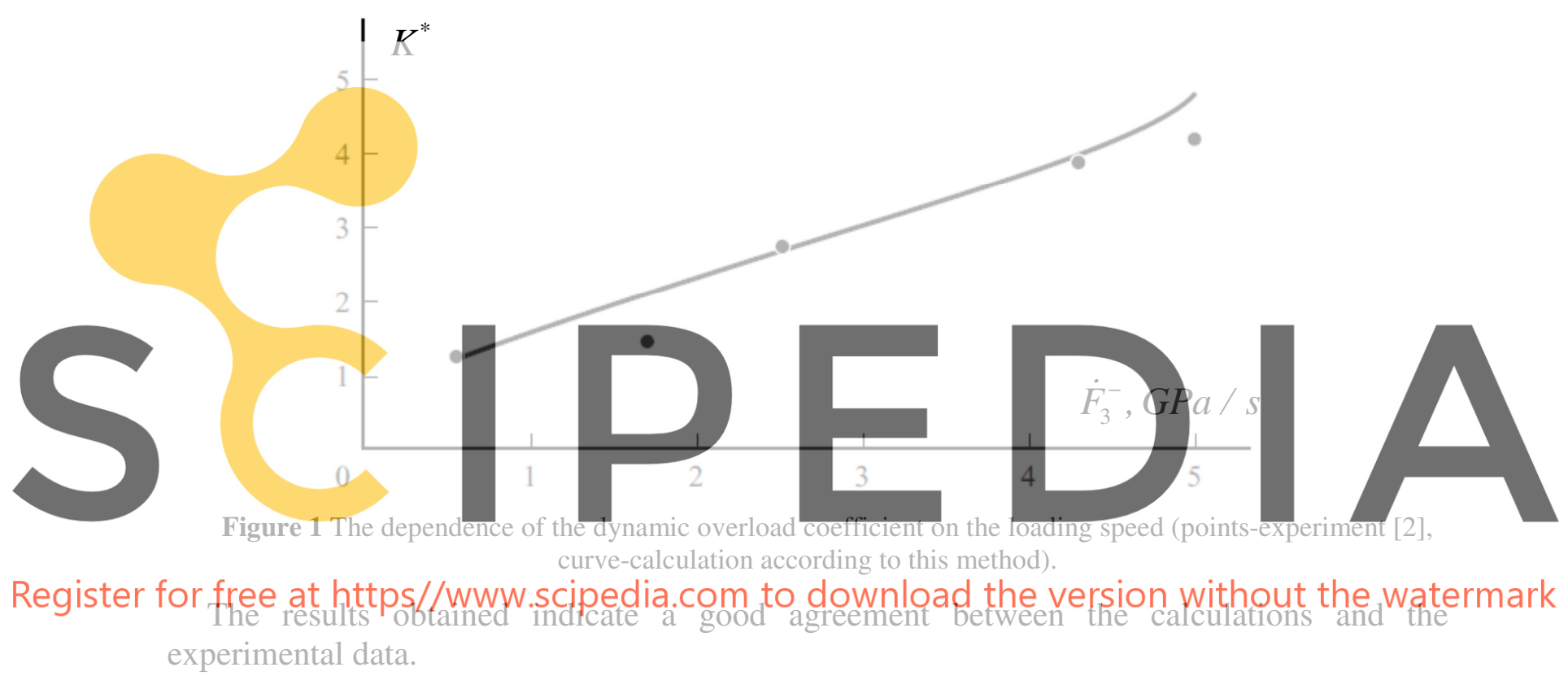

Figure 2 shows the characteristic forms of stability loss under static and dynamic loads with different external pressure velocities, considering the preliminary internal pressure $\bar{F}_{3}^{+}$ $=0.42$.

It follows from the above results that an increase in the external pressure velocity leads to a significant increase in the dynamic overload coefficient, and the tendency to increase the number of waves along the circumference and along the length of the shell with an increase in the loading speed, noted in [2], is also confirmed. 


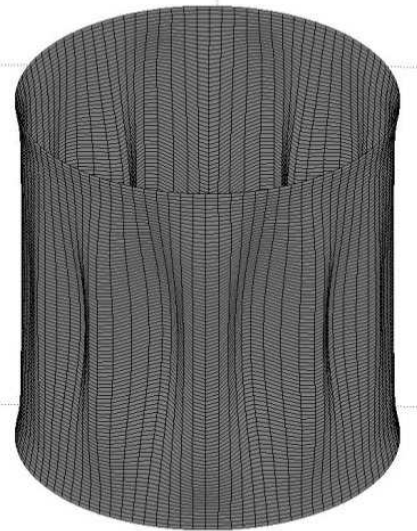

a)

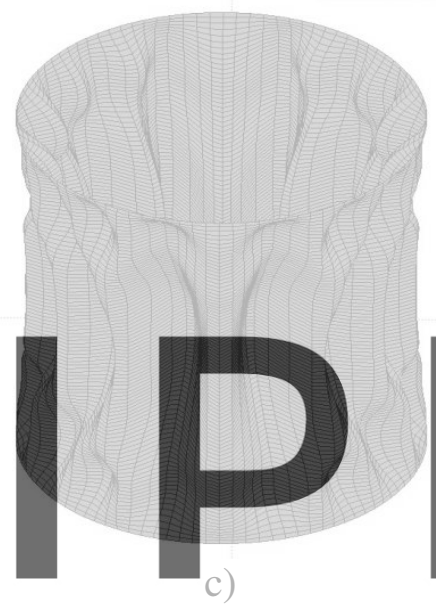

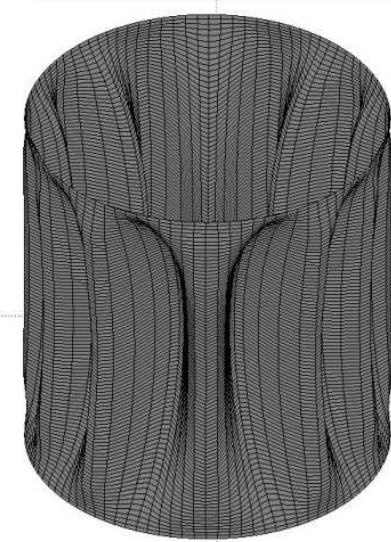

b)

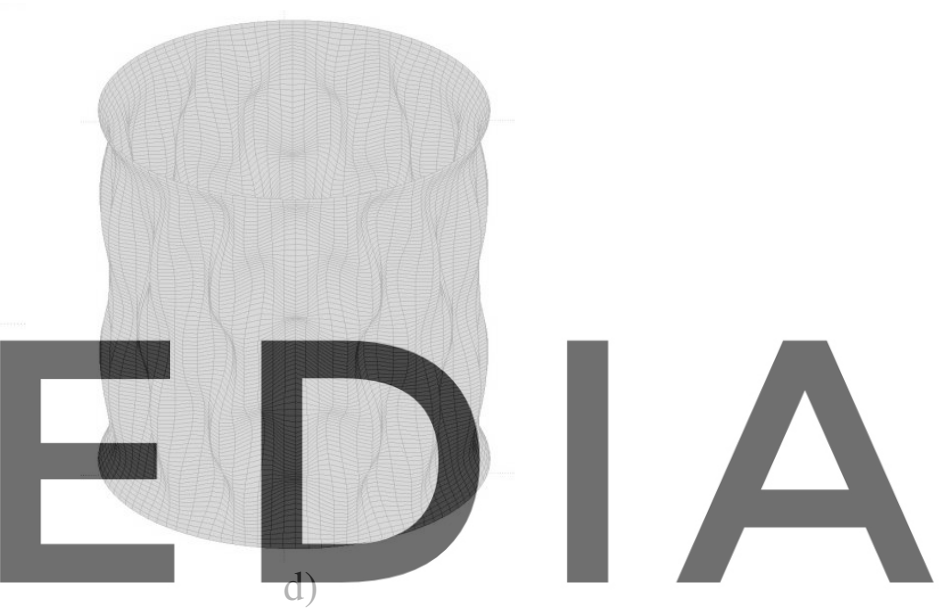

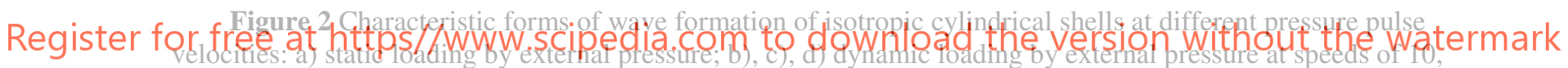

\section{0, $50 \mathrm{GPa} / \mathrm{sec}$}

Next, we studied the effect of reinforcement and advanced internal quasi-static pressure on the buckling of cylindrical shells under dynamic loading of axial compression, made of composite material with the following geometrical and physical-mechanical parameters of the material: $\quad R=0.072 \mathrm{~m} ; \quad R / h=112 ; \quad L / R=2.2 ; \quad E_{11}=200 \quad \mathrm{GPa} ; \quad E_{22}=E_{11} / 30$; $G_{12}=G_{13}=G_{23}=E_{22} / 2 ; v_{12}=0.25, \rho=1800 \mathrm{~kg} / \mathrm{m}^{3}$.

Figure 3 shows the absolute values of the maximum deflections of the shell over time for various reinforcement angles and preloading levels with quasi-static internal pressure under dynamic compression at a speed of $40 \mathrm{GPa} / \mathrm{sec}$. 


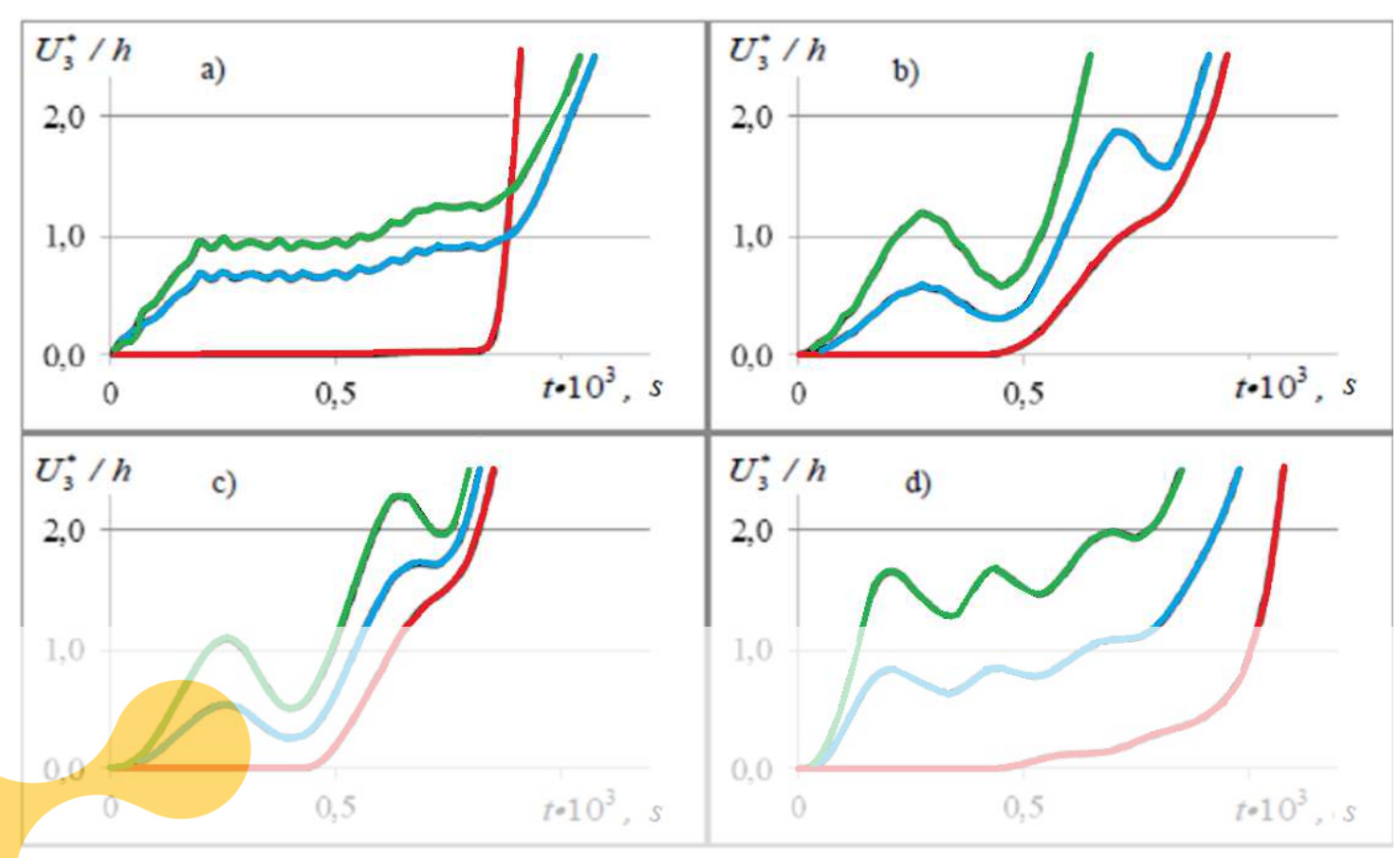

Figure 3 Dependences of absolute values of maximum deflection of shell vs. time for the rate of dynamic axial compression $40 \mathrm{GPa} / \mathrm{s}$ without preloading - red curves, considering preliminary internal static pressure $F_{3}^{+}=0.6$ and 0.9 - blue and green curves at reipforcement angles: $\left.90^{\circ}(\mathrm{a}), 60^{\circ}(\mathrm{b}), 45^{\circ}(\mathrm{c}), 15^{\circ} \mathrm{rd}\right)$ relative the length of
shell generatrix, respectively
The analysis of the level of internal pressure on the loss of stabjlity of shells with a
reinforcement angle of $90^{\circ}$ proyes that the shells subjected to axial loading exhibit los of
stability due to formation of a dense network of dianond-shaped dents elonated in the circumferential direction. Then, with increasing internal pressure, the loss of stability with the

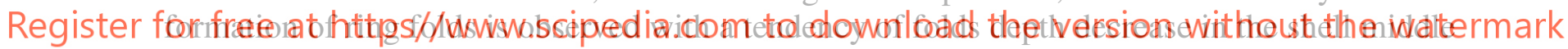
part. For the shells with reinforcement angles of $60^{\circ}$ and $45^{\circ}$ this tendency becomes dominant. In addition, the number of annular folds is being reduced. The shells with a reinforcement angle $15^{\circ}$ lose stability with strongly pronounced corrugations, the height of which decreases with growing level of internal pressure.

From the results obtained, it follows that the level of preliminary internal pressure, significantly affects the characteristic forms of buckling rather than the value of the critical pulse of axial compression. 


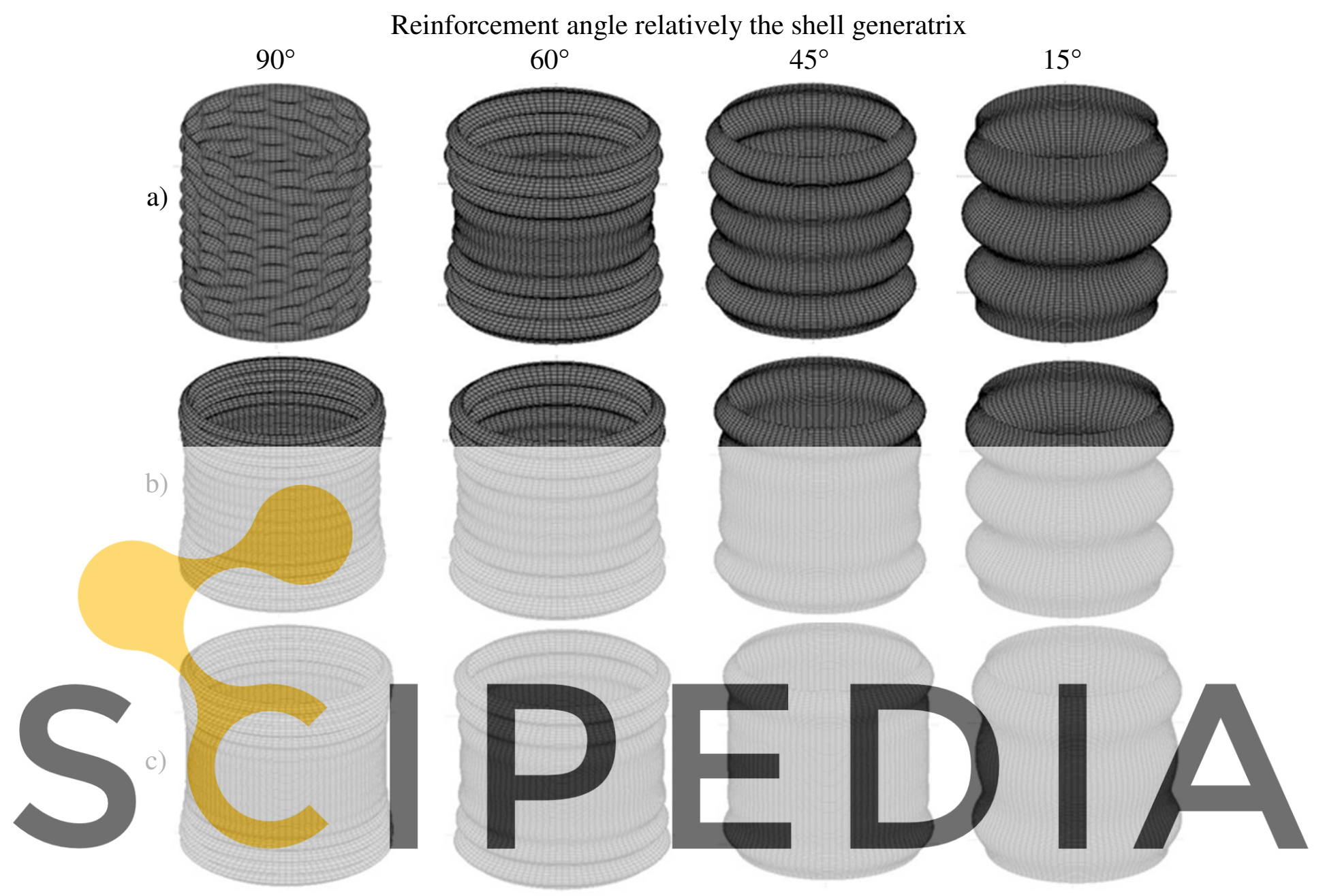

Register for free at https//www.scipedia.com to download the version without the watermark

Figure 4 Characteristic buckling forms of composite cylindrical shells under loading by dynamic axial

compression pulse at a rate of $40 \mathrm{GPa} / \mathrm{sec}$ for different reinforcement angles and levels of internal pressure $F_{3}^{+}=$

$$
0(\mathrm{a}), F_{3}^{+}=0.6(\mathrm{~b}) \text { and } F_{3}^{+}=0.9(\mathrm{c}) \text {, respectively }
$$

\section{CONCLUSIONS}

Preloading with internal quasi-static pressure during subsequent dynamic compression has a significant effect on the characteristic configurations of the stability loss of composite cylindrical shells and, to a lesser extent, on the value of the critical momentum of axial compression.

\section{ACKNOWLEDGMENTS}

The work was carried out with the financial support of the Ministry of Science and Higher Education of the Russian Federation (task 0729-2020-0054). 


\section{REFERENCES}

[1] Manevich, L. I., Mikhailov, G. V., Pavlenko, I. D., Prokopalo, E. F. (1977). Research on the stability of shells at a joint action of static and dynamic loads. Prikl Mekh XIII, 1, 2732.

[2] Baskakov,V.N.,Kostoglotov,A. I., Shvetsova, L.A. (1982). Investigation of the dynamic stability of smooth cylindrical shells. Problemy Prochnosti, 5, 31-33.

[3] Bendyukov, V. V., Deryushev, V. V. (1995) Dynamic short-wave instability of thinwalled cylindrical shells at the local action of an external pressure pulse. Problemy Prochnosti, 4, 36-43.

[4] Skurlatov, E. D. (1972). An experimental study on the behaviour of cylindrical shells at dynamic loadings. Problemy prochnosti, 9, 79-83.

[5] Dubrovin, V. M., Butina, T. A. (2015). Modeling the dynamic stability of a cylindrical shell at the action of an axial compressing load. Mechanics of Composite Materials, 6, $46-57$.

[6] Smirnov, I. V., Lamzin, D. A., Konstantinov, A. Y., Bragov, A. M., Lomunov, A. K. (2018). A unified experimental-theoretical approach to predict the critical stress characteristics of failure and yielding under quasi-static and dynamic loading. Engineering Fracture Mechanics.

[7] Volkov, I.A., Igumnov, L. A., Litvinchuk, S.Y., Vorobtsov, I.V. (2018). Modeling dynamic deformation and failure of thin-walled structures under explosive loading. EPJ Web of Conferences,
[8] Viktorov I. V., Tovs shells. Modern problems of
[9] Jansen, E. L. (2005 simplified analysis.
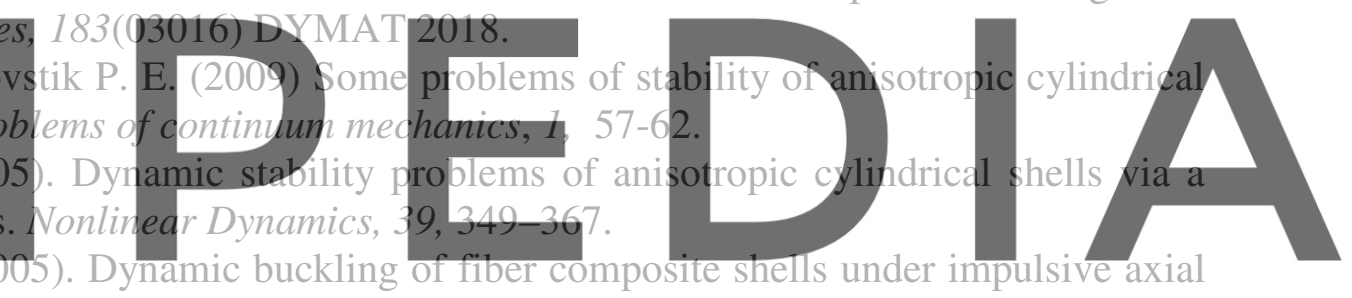

[10] Bisagni, C. (2005). Dynamic buckling of fibe
compression. Thin-Walled Structure, 43, 499-514

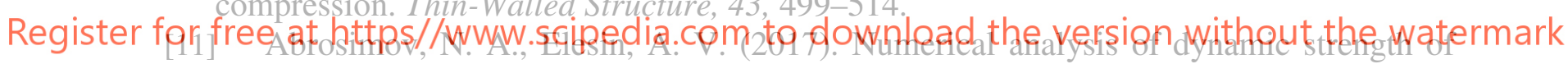
composite cylindrical shells under multiple-pulse exposures. Nizhni Novgorod, Problemy prochnosti i plastichnosti, 79(4), 450-461.

[12] Abrosimov, N. A., Bazhenov, V. G. (2002). Nonlinear Problems of dynamics of composite structures. Nizhni Novgorod: Izd NNGU, 400. 